\title{
Artigo
}

\begin{abstract}
Resumo
Este artigo consiste na releitura do caso clínico do pequeno Hans, problematizando acerca da dificuldade presente na tarefa de educar e tratar simultaneamente uma criança. Mesmo reconhecendo a importância desse estudo para o desenvolvimento da teoria freudiana sobre a sexualidade infantil, nossa discussão recairá sobre o que compreendemos como função "educativa" exercida por Max Graf. Considerando esse caso como uma experiência que inaugura a proposta freudiana de 1933 sobre uma educação psicanaliticamente orientada, conclui-se que, ocupado na função de analista/ educador do próprio filho, Graf acaba permitindo o acesso absoluto de Hans à mãe, acentuando seu fracasso enquanto agente da castração.

Descritores: caso clínico; pequeno Hans; psicanálise; educação.
\end{abstract}

\section{O CASO HANS \\ E A EDUCAÇÃO \\ PSICANALITICAMENTE \\ ORIENTADA: LEITURA \\ CRÍTICA DE UMA \\ EXPERIÊNCIA INAUGURAL}

Paula Julianna Chaves Pinto

Maria Celina Peixoto Lima

DOI: http//dx.doi.ors/10.11606/issn.1981-1624.v21i1p80-95.

\section{Introdução}

$\int_{-1}^{-1}$ relevante iniciarmos nosso percurso reafirmando o fato de que o caso clínico do pequeno Hans ocupa um lugar de destaque na história da psicanálise, não só por se tratar do primeiro tratamento analítico de uma criança, mas, sobretudo, pelo espírito inovador das ideias advindas da exploração, podemos dizer, pioneira, dos fantasmas infantis. No entanto, o centro de nossa discussão recairá

- Doutoranda em Psicologia pela Universidade de Fortaleza (Unifor), Fortaleza, CE, Brasil.

- - Professora do Programa de Pós-Graduação em Psicologia da Universidade de Fortaleza (Unifor), Fortaleza, CE, Brasil. 
sobre aquilo que poderia ser compreendido como uma função "educativa" exercida pelo pai da criança. Cabe a nós também lembrarmos que a condução do tratamento psicanalítico de Hans foi realizada por seu próprio pai, Max Graf (1873-1958).

Desde o ano de 1902, Max Graf era convidado, junto com outros pensadores da psicanálise, a se reunir com Freud em discussões semanais que ficaram conhecidas como encontros da Sociedade Psicológica das Quartas-Feiras. Esses encontros duraram por volta de cinco anos, sendo depois substituídos por uma verdadeira instituição psicanalítica, de tipo associativo, como uma espécie de modelo daquilo que posteriormente viria a ser a International Psychoanalytical Association (IPA) (Roudinesco \& Plon, 1998).

Esse grupo reunia-se em torno da figura de Freud e era composto por homens insatisfeitos com o discurso científico de sua época. Partilhavam utopias e aspirações a um mundo que considerasse as questões inconscientes, os sonhos e a sexualidade. Estavam impelidos a debater e discutir sobre a compreensão do semelhante, mas a curiosidade na solução dos próprios conflitos, de suas infâncias e identidades também era latente (Roudinesco \& Plon, 1998).

$\mathrm{Na}$ biografia de Freud, Gay (2005) apresenta uma rememoração de Max Graf acerca dessas reuniões em que ele descreve sua atmosfera, afirmando que após um quarto de hora de conversas sociais, iniciava-se uma discussão, mas a palavra final e decisiva era sempre proferida pelo próprio Freud que, ao falar, mostrava como as investigações psicológicas desenvolvidas até então se apresentavam superficiais. Ele ainda comenta acerca da presença de Max Graf no grupo de leigos que frequentava essas reuniões e como sua presença era apreciada por Freud, justamente por temer que a psicanálise pudesse vir a tornar-se monopólio dos médicos.

Nesse primeiro momento de necessidade de novas descobertas que pudessem fazer avançar a teoria psicanalítica, Freud estimula seus companheiros das reuniões a realizarem observações de seus filhos em suas residências 
e a trazerem comentários a respeito delas para serem discutidos coletivamente. Com essas observações, Freud pode reunir material e comprovar sua tese da atividade sexual infantil e seus mais variados desdobramentos, mas agora não só a partir da rememoração encontrada na clínica com adultos, mas também a partir da observação direta das próprias crianças.

Um dos primeiros a acatar essa ideia de observação direta das crianças foi Max Graf, que com sua esposa começou a registrar suas observações do comportamento do filho Hans desde seus três anos. A história clínica propriamente dita chegará ao formato que conhecemos somente mais de um ano e meio depois, quando a fobia de cavalos apresenta seus primeiros sinais.

O que Freud faz nesse caso segue os mesmos princípios técnicos utilizados na época da clínica com adultos, ou seja, interpretar e revelar ao paciente o sentido dos desejos edípicos e da angústia de castração. A especificidade aqui é que essas interpretações eram feitas a partir dos fatos registrados pelo pai da criança. A rotina de registros e referências a Freud fez com que Hans o chamasse de professor e se habituasse a pedir a seu pai que lhe escrevesse cartas contando sobre suas inquietações.

Essas diretrizes psicanalíticas utilizadas por Freud no curso do tratamento nos permitem acompanhar a eclosão da angústia e da fobia na criança, revelando a assertiva de que o "Freud clínico e o Freud teórico nunca se perdiam de vista" (Gay, 2005, p. 242). Na narrativa do texto vemos a alternância entre a escuta do paciente (feita pelo pai de Hans) e a análise de suas falas e as subsequentes interpretações sobre o sintoma (na maior parte feita por Freud). Esse arcabouço se soma a uma reflexão teórica rigorosa pautada nos conhecimentos construídos até o momento em relação ao Édipo e à castração.

\section{O método inquisitório de Max Graf e a saída pela fobia}

Embora reconhecendo a importância desse caso clínico enquanto norteador para o desenvolvimento acerca das teorias sexuais infantis e das primeiras formulações sobre o complexo de Édipo, nossa leitura do caso busca problematizar, mais especificamente, a dificuldade 
presente no caso do pequeno Hans, no qual vemos o acúmulo das tarefas de educar e tratar simultaneamente uma criança. Provavelmente movido pelo interesse em confirmar seus avanços sobre a vida sexual infantil, desenvolvidos nos "Três ensaios sobre a teoria da sexualidade", Freud (1905/1996a) não se detém nos aspectos transferenciais envolvidos entre o paciente, o pai e ele próprio.

Em todo o texto, Freud parece defender a postura do pai de Hans em conduzir o tratamento do filho, mostrando que muitas das dificuldades encontradas por ele seriam invariavelmente obstáculos em qualquer situação. Max Graf e sua esposa foram alguns dos primeiros adeptos da psicanálise e decidiram criar o filho de acordo com os princípios freudianos, ou seja, com o mínimo de coerção possível, divertindo-se com sua curiosidade sexual. Esse estilo de criação, porém, não impediu a eclosão de um medo paralisante de ser mordido por um cavalo, fazendo-o evitar os lugares que poderia vê-los e desencadeando uma fobia. Segundo Gay (2005), "Max Graf, ao mesmo tempo pai, herói, vilão e curandeiro particular do filho, começou a conversar com o garoto e a interpretar os significados das fobias do pequeno Hans, informando Freud assídua e detalhadamente" (p. 243).

Graf estava sempre inclinado a eleger a mãe da criança como a fonte da angústia de Hans, exatamente por sua excessiva ternura, bem como a atividade masturbatória do garoto. Freud (1909/1996b) chega a defender textualmente a mãe de Hans, chamando-a de devotada e admirável, afirmando que ela estava predestinada a 
desempenhar um papel bem difícil, mas não deixa de salientar essas acusações do pai de Hans no seu excesso de demonstrações de afeto para com a criança, bem como a frequência e a facilidade com que a mãe o levava para sua própria cama.

Contudo, depois do caso clínico de Dora, Freud (1905/1996c) mostrava-se mais cauteloso e preferia esperar um pouco mais antes de fornecer um diagnóstico. Gay (2005) afirma que Freud levava muito a sério os relatos que recebia de Graf, por mais absurdos ou triviais que pudessem parecer. Era a partir desses relatos que Freud orientava os próximos passos que o pai/analista deveria percorrer na condução do caso:

Combinei com o pai de Hans que ele diria ao menino que tudo aquilo relacionado com cavalos não passava de uma bobagem. Seu pai iria dizer que a verdade é que ele gostava muito de sua mãe e que queria que ela o levasse para sua cama. A razáo por que ele tinha então medo de cavalos se explicava por ele se haver interessado muito pelos seus pipis. (Freud, 1909/1996b, p. 33)

Outras passagens do texto, além da supracitada, nos comprovam as diversas atuações de Freud na elucidação do caso a partir da condução do pai de Hans. Essa forma particular de condução de uma análise não deixou de ser problemática, e Freud precisou, em muitos momentos, esclarecer os leitores acerca disso por observar erros técnicos na condução que Graf fez do tratamento.

Além disso, numa das poucas observações sobre a técnica nesse relato, Freud chega a criticar o pai de Hans por pressionar demais o filho, mostrando que ele perguntava excessivamente e investigava de acordo com seus próprios pressupostos, ao invés de deixar a criança se expressar. Interrompe a exposição do texto na tentativa de justificar, inclusive, que a análise de Hans fica mais obscura devido ao método inquisitório do pai no curso do tratamento.

Nesse ponto devo acrescentar algumas palavras. O pai de Hans estava fazendo perguntas demais, e estava pressionando o inquérito através de suas próprias linhas, em vez de permitir ao garotinho que expressasse seus sentimentos. Por essa razão a

84 Estilos clin., São Paulo, v. 21, n. 1, jan./abr. 2016, 80-95. 
análise começou a ficar obscura e incerta. Hans tomou seu próprio caminho e não produziria nada se fossem feitas tentativas de tirá-lo deste. (Freud, 1909/1996b, pp. 63-64)

Nessa sequência, Freud ainda alerta que alguns detalhes do caso foram muito mal enfocados pelo pai de Hans e faz um alerta a seus leitores que ainda não haviam conduzido uma análise: de não tentar compreender tudo de uma vez, dando um tipo de atenção não tendenciosa para os pontos que surgissem e aguardassem os posteriores desenvolvimentos.

Mas não é exatamente assim que vemos Graf conduzir o caso, e o engodo desse acúmulo de funções é destacado por Freud ao afirmar que no início do tratamento, o pai dizia à criança, de antemão, o que estava por vir, enquanto Hans "seguia sua orientação e vinha trotando atrás; mas agora era Hans quem estava abrindo caminho na frente, tão rapidamente e tão firmemente que seu pai encontrou dificuldade em acompanhá-lo" (Freud, 1909/1996b, p. 97).

Vemos, portanto, que ao longo do texto não só o método inquisitório de Graf fora criticado, mas vemos também a ressalva de que esse acúmulo de funções influencia na história do tratamento, trazendo impactos para a criança. Ao falar "em análise" para o pai (e indiretamente à Freud), observava-se uma discrepância entre o que Hans dizia e aquilo que pensava, o que confirma a incapacidade do material inconsciente em ser controlado pela 
criança, forçando-se sobre ele e, em parte, isso também se devia ao fato de que "o conteúdo de seus pensamentos provocava reservas em relação às suas relações com seus pais" (Freud, 1909/1996b, p. 97).

Mas mesmo com esse método um tanto inquisitório, Freud não deixava de encorajar Graf a prosseguir com o acompanhamento psicanalítico do filho. É essa questão que nos leva a pensar que o trabalho com Hans anunciaria os primórdios da proposta freudiana de 1933 sobre uma educação psicanaliticamente orientada, cabendo-nos a pergunta: seria essa a função educativa do pai?

Será a partir da interpretação que Lacan faz do mesmo caso que teremos a oportunidade de entender que Max Graf apresenta-se justamente como um pai incapaz de exercer a função paterna enquanto ordenadora do campo do desejo e representante da lei. $\mathrm{Na}$ psicanálise lacaniana temos acesso a uma teorização acerca do nome-do-pai, tendo este uma função estruturante no psiquismo infantil, situando a criança como sujeito desejante e não mais como objeto de desejo do Outro. O peso do simbólico vem atrelado ao pai e é esse quem deverá conduzir a criança no mundo da linguagem, da lei e do significante.

Se lembrarmos dessa experiência inaugural do caso Hans, veremos de que forma a criança foi construindo saídas possíveis para sua fobia, oferecendo-nos indícios de que o desfecho de seu Édipo foi atípico justamente pela necessidade de uma suplência, ou seja, a criança utilizou o medo de cavalos para tentar unir todo o conjunto daquilo que lhe faltava no momento e poderia conduzi-lo ao simbólico. De tal maneira, o cavalo representava ao mesmo tempo o pai, o falo, a irmãzinha e tudo o mais que lhe faltava (Lacan, 1999).

Lacan (1999) entende que essa saída utilizada por Hans fica muito clara em seu último sonho quando, no lugar do pai, o encanador é que será convocado como um ser imaginário e potente que aparece para retirá-lo de uma posição de assujeitamento. Mostra que essa posição é justamente o que instaura centros de medo na criança, e a partir deles irá girar o restabelecimento de sua segurança.

O medo, algo que tem sua origem no real, é um elemento de asseguração do menino. Graças a seus medos, ele dá um para-além ao assujeitamento angustiante do qual se apercebe no momento em que aparece a falta desse domínio externo, desse outro plano. Para que ele não seja pura e simplesmente um assujeito, é necessário que apareça alguma coisa que lhe meta medo. (Lacan, 1999, p. 196)

86 Estilos clin., São Paulo, v. 21, n. 1, jan./abr. 2016, 80-95. 
Essa questão é levantada por Lacan para assinalar que o Outro a quem Hans se dirige é a mãe. Mesmo mostrando que o pai não desempenha seu papel, entendemos que se trata menos das relações pessoais entre o pai e a mãe e sim, o mais importante, das relações da mãe com a palavra do pai. O autor salienta a função da mãe em fundar o pai como mediador daquilo que está para além de sua própria lei, o nome-do-pai ligado à enunciação da lei. Assim, o pai se instaura como aquele que pode ser aceito ou não pela criança como o que priva ou não priva a mãe de seu objeto de desejo.

Não é exatamente assim que encontramos a atuação de Max Graf na condução do caso. Por mais presente e amistoso que se mostrasse ao filho, inclusive preocupando-se em levá-lo a Freud, ainda assim aparece totalmente inoperante na medida em que aquilo que diz não produz efeito na mãe de Hans, que se mantém numa posição ambígua em relação à criança. Ao mesmo tempo que essa mãe é castradora e ameaçadora, papel que deveríamos ver atribuído ao pai, ela não hesita em permitir o acesso da criança à sua intimidade, à sua cama à noite, enfim, chegando até a encorajá-lo a isso. O que resta à criança é encarnar o falo para a mãe, mantendo-se nessa posição de assujeito, a grande fonte de toda sua angústia e fobia (Lacan, 1999, p. 197).

\section{A proposta freudiana de uma educação psicanaliticamente orientada}

Com o levantamento dessas referências acerca do lugar particular em que se encontra o caso clínico do pequeno Hans, podemos nos questionar sobre o impacto dessa obra nos pressupostos freudianos em relação à criança, ao infantil e à educação.

Nas “Novas conferências" de 1933, especialmente na Conferência 34 (Freud, 1933/1996d), podemos encontrar a tentativa de Freud em relacionar a aplicabilidade 
da psicanálise à educação, especificamente no tocante à educação de crianças. Isso ocorre por causa da cobrança dos muitos adeptos da psicanálise naquele momento, em ver a posição de Freud acerca da possibilidade de atendimento psicanalítico com crianças, assunto que ainda se encontrava envolto em querelas teóricas e técnicas.

Nessa conferência, Freud aponta na direção de que a psicanálise teria muito a contribuir com o trabalho da educação e que este não deveria ser apenas profilático, no sentido de uma busca pela prevenção das neuroses e, sob nenhuma hipótese, deveria ser confundido com a intervenção psicanalítica ou por ela substituído.

Ele reconhece a importância especial dos primeiros anos da infância, especificamente até os cinco anos de idade, dando alguns motivos para tal. Primeiramente, pelo surgimento da sexualidade, que deixa fatores causais decisivos para a vida sexual posterior, e em segundo porque as impressões desse período da infância irão incidir sobre um ego imaturo e atuarão sobre ele como traumas. Acredita que o ego infantil não conseguiria se adequar aos impactos que esses traumas poderiam causar, a não ser pelo mecanismo da repressão, deixando a infância como um período suscetível para uma doença posterior, além de distúrbios funcionais (Freud, 1933/1996d).

Freud afirma ainda que a dificuldade da infância reside no fato de que a criança precisa assimilar a evolução cultural que a precede, além de adquirir controle de seus próprios instintos para adaptar-se socialmente, tudo isso num curto espaço de tempo. Sabemos que a criança realmente só poderá efetuar determinadas modificações no curso de seu desenvolvimento, mas "muitas coisas devem ser impostas à criança pela educação" (Freud, 1933/1996d, p. 145).

É nesse ponto específico que Freud irá reconhecer o fato de que muitas crianças atravessam uma fase neurótica em seu curso desenvolvimental, impondo, portanto, medidas profiláticas, comparando essas medidas às vacinas contra determinadas doenças, antes mesmo de a criança ser por elas infectada. Mostrando uma argumentação histórica e social, vemos que Freud irá discorrer acerca do 
dilema da educação, já debatido anteriormente em duas outras conferências (Freud, 1917/1996e, 1917/1996f) acerca da supressão dos instintos e suas possíveis consequências no psiquismo da criança.

A menos que o problema seja completamente insolúvel, deve-se descobrir um ponto ótimo que possibilite à educação atingir o máximo com o mínimo de dano. Será, portanto, uma questão de decidir quanto proibir, em que hora e por que meios. E, ademais, devemos levar em conta que o fato de que os objetos de nossa influência educacional têm disposiçóes constitucionais inatas muito diferentes, de modo que é quase impossível que o mesmo método educativo possa ser uniformemente bom para todas as crianças. (Freud, 1933/1996d, p. 147)

É ao considerar essas limitações impostas ao exercício do educador, especialmente o fato de ter que reconhecer a individualidade constitucional da criança, inferir o que pode estar se passando em sua mente, oferecer-lhe quantidades exatas de amor e manter, ao mesmo tempo, um nível eficaz de autoridade, que Freud (1933/1996d) afirma que "a única preparação adequada para a profissão de educador é uma sólida formação psicanalítica" (p. 148).

É dessa assertiva que surge a ideia de um educador analisado, com algum tipo de experiência particular com as questões inconscientes ou, pelo menos, com informação psicanalítica. Ele entende que, para realizar o máximo possível e prejudicar ao mínimo, 
parece-lhe que a análise dos mestres e educadores equivaleria a uma medida preventiva mais eficaz que a das próprias crianças. De qualquer forma, o que nos parece é uma sugestão de utilização de algumas noções oriundas da psicanálise para se repensar os métodos educativos, em especial, compreender que a tarefa primeira da educação está no fato de ensinar à criança o controle das pulsões.

Boa parte dessas considerações de Freud acerca da educação correspondia ao papel dos pais, dos professores e das possibilidades de aplicação da psicanálise nesse campo, mas aos poucos suas considerações vão se modificando, especialmente em decorrência de sua prática clínica e de novas premissas teóricas. Schmidt (2011) acredita que Freud não apostara todas suas fichas numa educação reguladora da quantidade de restrição ou satisfação pulsional no objetivo de prevenção das neuroses e perversões, mas que alimentara a esperança em outra educação, psicanaliticamente esclarecida, na qual as atitudes de pais e professores na relação transferencial com as crianças pudesse alterar a situação atual do fazer pedagógico nas gerações futuras, justamente pelo cumprimento imperfeito de sua missão.

Foi exatamente esse pensamento que pudemos observar no relato do caso do pequeno Hans, foco de nosso trabalho. Freud ainda vê essa ilusão profilática no tratamento das crianças, mas ainda mantendo a esperança de uma alteração dos objetivos da educação, mesmo que somente para as gerações futuras, pois naquele momento sua crítica era justamente no fato de que a educação só havia pegado para si a tarefa de suprimir os instintos, sendo essa influência decisiva, muitas vezes, na própria ocorrência da doença. E assim sugere a substituição dessa por outra tarefa, que seria a de fazer o indivíduo capaz de tornar-se um membro civilizado e útil à sociedade, com o mínimo de sacrifício possível da sua própria atividade.

Nesse caso, a informação recebida pela psicanálise sobre a origem dos complexos patogênicos e sobre o núcleo de qualquer afecçáo nervosa pode reclamar, com justiça, que merece ser encarada por educadores como um guia inestimável na sua conduta em relação às crianças. (Freud, 1909/1996b, p. 144)

Muitos foram os trabalhos que se debruçaram acerca dessa proposta freudiana de uma educação psicanaliticamente orientada. Lembrando também as premissas apresentadas por Freud (1930/1996g) em "O mal-estar na civilização", em que se afirma a impossibilidade de uma formalização integral de uma educação de cunho humanista baseada na psicanálise, Kupfer (2007) nos mostra 
que uma educação psicanaliticamente orientada e capaz de contribuir para o progresso da humanidade deixa de fazer sentido. Afirma ainda que o máximo que a educação pode fazer é "esforçar-se em transformar o húmus de nossas piores disposições em algo que preste, e isso os educadores já fazem há séculos” (p. 14). Isso significa que não haveria o que ser "melhorado" nas práticas educativas, justamente pelo fato de que já cumprem sua obrigação em submeter a criança à ordem simbólica pela travessia do Édipo, fundando assim sua condição humana miserável, caindo por terra uma esperança de educação analítica com sentido profilático em relação às neuroses, já que delas não se escapa ou se evita, pois são o fundamento de nossa subjetivação (Kupfer, 2007).

Será que poderíamos afirmar, diante do que foi exposto, que Graf se inspira nessa ilusão profilática freudiana, conduzindo a história de Hans para a neurose, justamente pelo fato de ter fracassado na função paterna, veiculadora da castração, tendo-se centrado demasiadamente na função de analista/educador do próprio filho?

\section{Educar e tratar: a conjugação de dois impossíveis}

Também são vastas as produções que discutem a aplicabilidade da psicanálise no campo da educação, porém, a grande maioria delas comunga do pressuposto freudiano que aponta esses fazeres para o âmbito das impossibilidades, lembrando os três ofícios impossíveis descritos por Freud (1937/1996h): governar, analisar e educar.

Mas salientamos que, ao falar dessa impossibilidade, Freud não a remete a uma estagnação do fazer, mas à impossibilidade do laço social. É isso que une esse três fazeres de forma problemática e ao mesmo tempo gera muitas reflexões acerca das possibilidades de interlocuções entre esses campos, especialmente entre 
a educação e a psicanálise, que comungam da necessidade de visão acerca dos processos de constituição do sujeito.

É exatamente por esse motivo que o caso clínico do pequeno Hans torna-se emblemático para aquilo que trazemos como proposta neste trabalho, justamente por observarmos que, ocupado na função de analista/educador do próprio filho, Graf acaba permitindo o acesso absoluto de Hans à mãe, acentuando seu fracasso enquanto agente da castração. Nossa indagação deriva exatamente desse acúmulo de funções, o que nos permite ainda questionar: será que ao se enrolar na função de pai, analista e educador, Max Graf não deixa Hans à deriva diante do desejo materno?

Podemos atestar, com aquilo que já fora exposto do caso, o movimento do pequeno Hans em se valer do que lhe resta das insígnias paternas, improvisando uma emenda na metáfora do nome-do-pai e, por meio dela, podendo gerar um significante fóbico para fazer a suplência do agente de castração. Como vimos, essa saída foi utilizada por Hans como solução justamente por não encontrar no pai o agente limitador do gozo, que ao ser vinculado ao falo e articulado à lei, pudesse lhe oferecer uma posição desejante, bem diferente daquele assujeitamento oferecido tão prontamente pelo desejo materno.

Assim como Freud, vimos que também Lacan denuncia o método demasiadamente inquisitório que Graf se utiliza para se aproximar do filho na tentativa de tratá-lo, chegando inclusive, em muitos momentos, a direcionar suas respostas para aquilo que esperava ouvir e depois repassar a Freud. Essa aproximação desajeitada foi geradora de todo tipo de mal-entendido na relação entre Hans e seu pai (analista?). Observando bem o caso clínico podemos atestar que Max Graf falha duas vezes com seu filho: no exercício da função paterna, falha na representação da lei e na interdição do gozo, e como analista falha ao conduzir as respostas da criança e fazer seus registros, apressando-se em compreender demais. Acreditamos também que é essa falha enquanto analista que o conduz a uma posição demasiadamente apoiada na figura do educador, ou seja, aquele agente que irá se pautar na orientação teórica da psicanálise e não em sua experiência própria com as questões do inconsciente (efeito de análise), como sugere Freud (1933/1996d) na já citada conferência.

Podemos até afirmar que, talvez por esse excesso de dedicação teórica, o pai de Hans tenha acabado permitindo que a fobia se instaurasse em definitivo, mesmo que esta já estivesse à espreita e oferecendo alguns traços no início de suas observações. Tal mostra 
de comportamento é somada a certa fragilidade na encenação da função paterna, fazendo-o testemunha da eclosão da fobia na criança, mesmo depois de tanto empenho em oferecer a ele uma "educação psicanaliticamente orientada".

$\mathrm{Na}$ única sessão de Hans com Freud, podemos vê-lo atuando enquanto pai simbólico, em carência até aquele instante, pois a relação da criança com o pai permanecia na ordem do imaginário. De tal forma que, ao narrar o mito edipiano para Hans, Freud permitiu ao pai entrar nessa triangulação e ainda introduzi-lo no próprio sintoma, conduzindo o caso para o que poderia se aproximar de uma solução naquele momento.

É por isso que quando Lacan (1995, p. 410) se pergunta: “o que é um pai?", nos responde apontando para aquele que nos introduz ao mundo humano e organizado pela ordem simbólica. Essa seria sua função e aquilo a que esse pai teria que enfrentar. Já ao analista, o que se reserva? Lacan (1995) nos responde que será apenas numa análise que poderemos descobrir o mínimo de exigências a que um pai real deve responder para que seja possível a transmissão à criança, de seu lugar nessa mesma ordem simbólica. De tal forma, podemos ver que o engodo do acúmulo das funções de educador e terapeuta não evitou a constituição da fobia em Hans, e ousamos dizer até que a favoreceu.

Ainda com Lacan (1995), veremos a dimensão clara do engodo que se tornou aquilo que conhecemos como a experiência inaugural de análise de uma criança e o direcionamento para uma cura satisfatória daquilo que se pode dizer a propósito de sua fobia. Isso se deu justamente "na medida em que interveio o pai real, que havia intervindo tão pouco até então, e que, aliás, só pode fazê-lo porque teve atrás de si o pai simbólico, que era Freud" (p. 235).

Finalizamos com uma lembrança que Roudinesco e Plon (1998) fazem de outra passagem célebre de Lacan quando diz em seu seminário de 1968-1969: "Hans não tem mais medo de cavalos, e depois?” (p. 310). Tal indagação, plena de sentido, nos traz à nossa atualidade acerca das terapias de caráter educativo-comportamental e das recorrentes críticas à psicanálise no que diz respeito à eficácia do tratamento das fobias. Embora curado de sua fobia infantil, o que sabemos da vida de Herbert Graf (verdadeiro nome do pequeno Hans) não nos permite sustentar a efetividade de uma cura. $\mathrm{Na}$ continuidade do texto citado anteriormente, obtemos informações de que a vida do pequeno, quando transformado em adulto, foi caracterizada pelo contraste entre o sucesso profissional e seus fracassos afetivos. Ao lado da brilhante carreira e da invenção de uma profissão, Herbert Graf experimentou uma vida de sofrimentos e, diferente do que afirma Freud ao fim da exposição do caso, nunca conseguira superar o choque causado pelo divórcio dos pais, 
estando sempre atormentado por conflitos conjugais e buscando até retomar uma análise, além de procurar se apresentar a Anna Freud em um congresso (Roudinesco \& Plon, 1998).

Para seu pai, Max Graf, o tratamento do filho não permitiu tampouco sua formação como analista. No entanto, as contribuições do estudo do caso Hans para o avanço do pensamento do campo psicanalítico não se restringem à confirmação da tese freudiana sobre a sexualidade infantil e sobre a origem da neurose do adulto nos complexos infantis, mas permanecem, bem depois, inspirando novas reflexões.

THE HANS CASE AND THE PSYCHOANALYTICALLY ORIENTED EDUCATION: CRITICAL READING OF AN INAUGURAL EXPERIENCE

\begin{abstract}
This article consists in a new approach to the clinical case of little Hans, questioning the difficult task of educating and simultaneously treating a child. While recognizing the importance of this study for the development of Freud's infantile sexuality theory, our discussion will be on what we understand as the "educational" function of Max Graf. Considering this case as an experience that introduces Freud's 1933 proposal of a psychoanalytically oriented education, it is concluded that, engaged in the function of analyst/educator of his own son, Graf enables the absolute access to Hans' mother, accentuating his failure as the castration agent.
\end{abstract}

Index terms: clinical case; little Hans; psychoanalysis; education.

EL CASO HANS Y LA EDUCACIÓN PSICOANALÍTICAMENTE ORIENTADA: LECTURA Y CRÍTICA DE UNA EXPERIENCIA INAUGURAL

\title{
Resumen
}

Este artículo consiste en una nueva lectura del caso clínico del pequeño Hans, problematizando acerca de la dificultad presente en la tarea de educar y tratar simultáneamente a un niño. Aun reconocemos la importancia de este estudio para el desarrollo de la teoría freudiana sobre la sexualidad infantil, nuestra discusión recaerá sobre lo que se entiende por "función educativa", ejercida por Max Graf. Considerando este caso como una experiencia que inauguró la propuesta freudiana del 1933 sobre una educación psicoanalíticamente orientada, se concluye que, al ubicarse en la función de analista/ educador de su propio hijo, Graf acabó permitiendo el acceso absoluto de Hans a la madre, acentuando su fracaso como agente de castración.

Palabras clave: caso clínico; pequeño Hans; psicoanálisis; educación.

\section{REFERÊNCIAS}

Freud, S. (1996a). Três ensaios sobre a teoria da sexualidade. In S. Freud, Edição standard brasileira das obras psicológicas completas de Sigmund Freud (J. Salomão,

94 Estilos clin., São Paulo, v. 21, n. 1, jan./abr. 2016, 80-95. 
trad., Vol. 7, pp. 117-229). Rio de Janeiro, RJ: Imago. (Trabalho original publicado em 1905)

Freud, S. (1996b). Análise de uma fobia de um menino de cinco anos. In S. Freud, Edição standard brasileira das obras psicológicas completas de Sigmund Freud (J. Salomão, trad., Vol. 10, pp. 11-134). Rio de Janeiro, RJ: Imago. (Trabalho original publicado em 1909)

Freud, S. (1996c). Fragmento da análise de um caso de histeria. In S. Freud, Edição standard brasileira das obras psicológicas completas de Sigmund Freud (J. Salomão, trad., Vol. 7, pp. 13-116). Rio de Janeiro, RJ: Imago. (Trabalho original publicado em 1905)

Freud, S. (1996d). Conferência XXXIV: explicações, aplicações e orientações. In S. Freud, Edição standard brasileira das obras psicológicas completas de Sigmund Freud (J. Salomão, trad., Vol. 22, pp. 135-154). Rio de Janeiro, RJ: Imago. (Trabalho original publicado em 1933)

Freud, S. (1996e). Conferência XXII: algumas ideias sobre desenvolvimento e regressão - etiologia. In S. Freud, Edição standard brasileira das obras psicológicas completas de Sigmund Freud (J. Salomão, trad., Vol. 16, pp. 343-360). Rio de Janeiro, RJ: Imago. (Trabalho original publicado em 1917)

Freud, S. (1996f). Conferência XXIII: os caminhos da formação dos sintomas. In S. Freud, Edição standard brasileira das obras psicológicas completas de Sigmund Freud (J. Salomão, trad., Vol. 16, pp. 361-378). Rio de Janeiro, RJ: Imago. (Trabalho original publicado em 1917)

Freud, S. (1996g). O mal-estar na civilização. In S. Freud, Edição standard brasileira das obras psicológicas completas de Sigmund Freud (J. Salomão, trad., Vol. 21, pp. 65148). Rio de Janeiro, RJ: Imago. (Trabalho original publicado em 1930)

Freud, S. (1996h). Análise terminável e interminável. In S. Freud, Edição standard brasileira das obras psicológicas completas de
Sigmund Freud (J. Salomão, trad., Vol. 23, pp. 223-270). Rio de Janeiro, RJ: Imago. (Trabalho original publicado em 1937)

Gay, P. (2005). Freud: uma vida para nosso tempo. São Paulo, SP: Companhia das Letras. (Trabalho original publicado em 1989)

Kupfer, M. C. M. (2007). Educação para o futuro: psicanálise e educação. São Paulo, SP: Escuta.

Lacan, J. (1995). O seminário, livro 4: a relação de objeto, 1956-1957. Rio de Janeiro, RJ: Jorge Zahar.

Lacan, J. (1999). O seminário, livro 5: as formaçôes do inconsciente, 1957-1958. Rio de Janeiro, RJ: Jorge Zahar.

Roudinesco, E., \& Plon, M. (1998). Dicionário de psicanálise. Rio de Janeiro, RJ: Jorge Zahar.

Schmidt, G. R. (2011). Sigmund Freud, da psicoprofilaxia à educação psicanaliticamente esclarecida: um percurso. Paidéia, 21(48), 119-127. doi: http://dx.doi.org/10.1590/ S0103-863X2011000100014

psijuchaves@hotmail.com Avenida Beira Mar, 3958/1203 60165-121 - Fortaleza - CE - Brasil.

celina.lima@unifor.br

Rua Carlos Vasconcelos, 590/201 60115-170 - Fortaleza - CE - Brasil.

Recebido em novembro/2015. Aceito em março/2016. 